\title{
The inclusion of ergonomic tools in the informational, conceptual and preliminary phases of the product design methodology
}

\author{
Ivan Luiz de Medeiros ${ }^{\mathrm{a}, *} ;$ Eduardo Concepción Batiz ${ }^{\mathrm{b}}$ \\ ${ }^{a}$ Department of Design - University of Joinville Region UNIVILLE, Campus - Bom Retiro - Joinville - SC - Brazil \\ ${ }^{\mathrm{b}}$ Department Professional Master's Degree in Production Engineering - Educational Society of Santa Catarina - \\ SOCIESC - Albano Schmidt Street, 3333 - Boa Vista CEP 89206-001 - Joinville - SC - Brazil
}

\begin{abstract}
The process of product development has received special attention as it is being recognized as a source of competitive gain. Through its systematic use companies reduce costs, increase quality and decrease development time. However, one can find products being launched on the market that cause dissatisfaction to its users, and in consequence if the customer feels harmed or injured he will no longer purchase a product from the same brand. This in regard only to the commercial aspect; usually the danger of an accident or injury is not even thought about. This paper is the basis of the dissertation master's degree and used a literature research to build the repertoire, analyzing the methodologies applied by product design engineers, designers and ergonomists. The analysis results demonstrate the inefficiency of the design methodologies ergonomic issues. The contribution of this work lies in the suggestion to include ergonomic tools in all phases of product development and the presentation of a table with the tools that points out its most suitable time of application and results.
\end{abstract}

Keywords: product design, ergonomics, product development methodology.

\section{Introduction}

Many design methodologies for product development are found in the specialized literature, some are more detailed, some more simplified. However all of them systematize the process development and agree that it gradually reduces risks and failure of a new product, as the development process phases advance, evaluating the risks of the project step by step.

This research is justified by the fact of finding new products currently on the market in which the design is not user-centric, ignoring relevant aspects of ergonomics. It is necessary to understand the importance of a methodology for integrated product design with ergonomics and its methods and tools. Design can be defined as the planning or the project of a model, resulting in the configuration of a product [9]. If this project is not performed based on a design methodology or by a trained professional, with theoretical and technical knowledge within the field of product development, such as ergonomics, materials, processes, among others, the result of this planning can cause problems in the user and product relationship, physical or cognitive problems at the time of use.

The product development process characterizes its activities by a systematization of phases and the use of various tools, each one with a function and importance. Three major phases in this process can be cited: informational, conceptual, preliminary; each one with its specific tools and activities [16].

Companies spend too much time trying to identify product attributes important to the customer. They invest in Investigative resources as benchmarketing competitors and focus groups, this information is transformed into lengthy documents describing the target customer and cost-effective model, exaggerating this analytical approach and objective. This type of behavior does not establish an emotional connection with customers. The user is not the

\footnotetext{
${ }^{*}$ Corresponding author. E-mail: ivan.medeiros75@gmail.com
} 
central part of the development process, the numbers are [12].

Some product development professionals who work in the area don't always have contact with the future users of the product to be designed and end up getting informations and characteristics pertinent to the project through third parties. Features and informations that are essential to the project end up with a discrepancy betwen the real need of the users and the product to be proposed. The designer, in this moment, needs subsidies and tools that minimize these problems in the project activity, anticipating future situations and problems. Thus it is important to understand the application of ergonomics in the projects. Ergonomics contributes to improve the product efficiency, reliability and quality, when applied in the design phase or even in the corrective actions of the products or artificial environments.

So, it is easy to understand the importance of a more efficient interaction in these areas of study, ergonomics and product design. The professional responsible for product design and artificial environments caractherizes his work based on physical and psychological needs of people in the society. Usability features are not fully disclosed as attributes for the project, sometimes because the design methodology does not address the ergonomics and other times due to the lack of knowledge about ergonomics itself. The use of ergonomics applicability and studies based on scientific data is relevant, since product design is a systemati,c creative conception and improvement process, in witch the main purpose of product development is to be used by a person or a certain group of people.

Ergonomics will be noticed and implemented when the cost/benefit analysis is compared and it is understood that the application of ergonomic tools will be perceived as an investment by users and consumers. This will require that the professional responsible for product development uses a design methodology that addresses ergonomics in the whole process.

Therefore, it is clear for this study the importance of knowing and systematizing design methodology, thus finding the best ergonomic tools that can be inserted in the phases of this product and/ or environment. design system .

\section{Literature Research}

\subsection{Design history}

The origin of the products developed with optimized function can be found since the beginning of mankind. Thus it was cited in the times of roman civil engineer and artist Vitruvius (80-10 BC) in many records in architecture [2].

One of the earliest and most complete work on project rules and configuration his "Ten books on the art of building" describes the close relationship between theory and practice. In the third chapter of his first book Vitruvius wrote a phrase that entered the history of Design: "All construction must comply with three categories: strength, utility and beauty" [2] Industrial Design, as we know it, is a concept from the mid 19th century, brought by the Industrial Revolution. A landmark for this period was the separation of designing and manufacturing, which so far were done by the same person: the craftsman. Separating the processes of conception and execution, and deploying the last one in numerous small phases of limited scope, the need of employing workers with high technical skills was eliminated. In the place of many skilled craftsmen, a good designer was enough to design the product, a good manager to oversee the production and a large number of unskilled workers to perform the phases, preferably as mere machine operators [2].

\subsection{Relevance of design methodologies}

The product development process has proven to be increasingly strategic and important for companies due to the strategic agility to launch new products and important for staying ahead of competitors. This demonstrates the importance of decisions in institutions that claim to be competitive.

It is a specific feature of development process that each project may present problems, difficulties and specific particular records, which means that the development activity is not a routine activity, as is observed in financial or production processes. The author also comments that the choices of alternatives in the beginning of the development cycle are responsible for about $85 \%$ of the final product cost. In other words, every other resolutions and decisions to be taken throughout the development cycle, after the early stages, determine the remaining $15 \%$ of the cost [16].

Promoting changes when the product is just a concept, an idea, involves less work and fewer resources than making changes when the projects and processes have already been set, when the tool has 
been designed and built, and especially when the production and distribution have been initiated [6].

Interventions in workplaces pay back in two years, although the effects of ergonomic design will have a greater life spam in the organization. On the other hand the author states that, in regard to new products, a good ergonomic design can make a difference in sales and company's competitive position [18].

So a good ergonomic design results in safer products, avoiding legal costs related to accidents and associated injuries. In general design methodologies are structured in the resolution of technical characteristics of the product and it has been noted that most companies that develop products only pay attention to ergonomics after solving the technical issues of a product.

\subsection{Costs of ergonomics in design}

The products are designed to be used by people. People manufacture, transport, install, maintain, clean and finally scrap or recycle them. And people have different characteristics, skills, abilities and limitations, which undergo changes over the time. The products are actually designed for people when those characteristics and variables are considered [7].

A study by Autoburn, a U.S.A ergonomic consulting firm, shows that when the ergonomics is considered in the project design phase, ie, occur as ergonomics design, the cost of Ergonomics will add only $0.5 \%$ to the project cost [7].

If the ergonomic considerations are only carried out during the details phase of the project, they will add between $2 \%$ and $3 \%$ to the project cost. If the ergonomics is not considered in the construction phase of the system, it can add up to $5 \%$ to the project cost. If it is considered only after the project is completed, the costs can represent an increase of $10 \%$ to $20 \%$ in the project costs. [7].

Ergonomists try to answer the social needs related to work and the sooner their participation in projects, the better, as more questions are pointed out [4].

Obviously, the ergonomics cost is substantially lower when considered at the beginning of a project, so, the ergonomics with better cost/benefit is the design ergonomics.

With the development of user-centered product from the earliest stages, it is clear, based on the authors cited in this paper, that it will reduce considerably the cost of the project thus avoiding further corrections and additions to the product cost.

The ergonomists take part in the project group as co-creators, ensuring that the specificity of ergonomics is incorporated throughout the design process; they contribute to the understanding and a better representation of the designed product users, as well as give several ergonomic recommendations with justified prioritizing. Their analysis are based on knowledge, methods and tools and allow them to advise the designer on the users in order to develop products tailored to their working methods, their, expectations and their needs, helping the designer to evaluate the consequences of choices made in terms of health, safety, comfort and efficiency [17].

\subsection{Product design methodology}

It is worth reminding the importance of applying a product development model, that as well as aiming its methods and tools to the users, also meets the market characteristics. For this purpose it is necessary to study a model or procedure development resulting in good solutions. That is, applicable and flexible ones that can adapt to the situations of each company.

The project methodology is understood as planned procedure with actual indications of conduct to be observed in the development and design of technical systems, through the use of project science and cognitive psychology and also from the experience with different applications [14].

It is necessary to observe the general objectives and developing strategies, mainly for the formal setting, as well as methods of solving problems or subtasks.

Some of the characteristics that the project methodology must have:

- Provide a problem-oriented procedure that, in principle, can be applied in any project activity, regardless of specialty;

- Encourage inventions and knowledge, facilitate the search for appropriate solutions;

- Be compatible with the concepts, methods and knowledge of other disciplines;

- Generate solutions not only by chance,

- Allow the solutions to be transferred to similar tasks;

- Be suitable for computer use;

- Be able to be taught and learned;

- Comply with cognitive psychology and ergonomics knowledge, making the work easier, saving time and avoiding wrong decisions;

- Facilitate the planning and control of team work in an integrated and multidisciplinary process for the product creation; 
- Be directed to development team project managers [14].

\subsection{Product design}

The beginnings of the design methodology go back to the 60 's, especially in the German design school HfG Ulm founded in 1952 in which this issue was intensely debated [2]. The motivation for this was the increase of the tasks given to designers in the industry at this time. Christopher Alexander, one of the fathers of the design methodology, in 1964 listed four arguments for the design process with its own methodology. They are:

- Design problems have become too complex to be treated just intuitively

- The amount of information needed to solve problems was increased in such a way that the designer alone cannot capture or handle it.

- $\quad$ The number of design problems has increased rapidly;

- The kind of design problems, compared with previous projects, changes so fast that it has become increasingly difficult to rely on previous experiences [2].

Some authors prefer to split the process in more stages, while others prefer more simplified processes. It doesn't matter as much as that the use of a methodology progressively reduces the risks of failure of new products, throughout the steps [1].

The whole process of innovation is long and complex, and subdivided into steps makes the development control easier. Some designers do not agree with the division of the project in stages, justifying that the process does not follow a linear order, tending to be random [1].

\subsection{Ergonomics methodology}

An important feature of ergonomic method is the involvement of users and project stakeholders, from the early stages, to avoid errors in design and to identify difficulties by listening to the users. The authors present a structured methodology as follows:

1) Initial planning: analyzing the nature of the project, formulation of questions for the product design planning;

2) Data capture to gather necessary information and check for possible alternatives;

3) Selection of alternatives: stage of selecting one of the developed alternatives;

4) Implementation: developing the selected alternative;
5) Evaluation: evaluating the impact of the project and set the necessary corrections [5].

The project is not developed in logical and linear steps, in practice every advance requires a return to the previous stages for review. To conclude that a work can be considered an "ergonomic design", it is necessary that the ergonomist takes part in all the stages, ensuring that the product has the ergonomic qualities desired by consumers or users [5].

\section{Analysis of the methodological phases}

For a better understanding of this work, the analysis was divided in three parts: "informational", "conceptual" and "preliminary." To understand properly the applicability of ergonomic tools, it is necessary to check its function and how to insert it in the product design methodology. Hereinafter it is suggested the most appropriate ergonomic tool that can be used in the phase in question. Since it is central to correctly determine the characteristics of the future product, it must be noted the relevance of the ergonomic aspects being present since the initial phase of the project. In order to do this, ergonomic tools must be incorporated to ensure greater reliability in the product development process.

\section{1 Informational phase}

The informational phase is the time for research. In this phase it is possible the use of many tools, each with a purpose and result.

A data capture tool that helps in this phase is the observation, systematic or unsystematic. Observing is a matter of practice. After all, one can only be critical to improve products or services if the observer understands what he is doing. To observe is to carefully transcribe the various day by day situations and perceive where users' activities, actions and behaviors can be improved.

The ergonomist makes use of systematic observation (which requires planning) in the diagnostic step, during the task analysis, when task behavioral activities are recorded, such as posture, triggered manipulations, communications and displacements. [11]. Unsystematic (unplanned) observations help in the first contact with users.

Another tool commonly used by ergonomists is interview, a talk addressed with clear objectives. It can be classified as informal, semi-structured or structured. In the informal ones, there isn't a 
particular script, differently from the structured, in which questions follow a previously prepared order. However, in semi-structured interviews, questions are also established in advance, but the interviewer directs the questions according to the answers.

In a questionnaire research tool, there may be those with open or closed answers. The closed questions questionnaire may have "yes" or "no" alternatives, hierarchy or multiple choice. They are instruments that have pre-established categories. Through the questionnaire, respondents can mark the alternative that best fits their character, their thinking or feeling. To apply this type of questionnaire, respondents must be familiar with the subject in question and the interviewer must know the group questioned. By analyzing the questionnaire answers, the project team can identify the users' wishes regarding specific questions about the product. Through this analysis, the list of user's requirements addresses the desirable characteristics of the product to be developed.

Task analysis determines the difference between the prescribed (planned) activity and the effectively performed task. Thus, discrepancies in the activities performed can be noticed. Task analysis aims to know in detail, of what comprises the task to be performed.

Observation, interviews, questionnaires and task analysis are ergonomic tools that are intended to identify users' problems and needs should be included in the informational phase.

Much of these analyses can be recorded for later analysis. Thereunto, one must make use of photography, interviews recording and filming, simple activities that, if used properly, become effective to keep record of inappropriate postures and interaction with the product related situations.

There are many ergonomic tools oriented to diagnose users' inappropriate postures. Below are listed some of the best known and used. If they are used in the product development informational phase, they can provide postural analysis that will help in developing the users' requirements.

The amplitude of these methods involves estimation techniques (biomechanics), muscle activity measurements (Electromyography analysis), subjective measurements (recording of discomfort) and numerous interpretative methods of postures and biomechanical analysis recording (OWAS, NIOSH, RULA, REBA and others), postures measurement (goniometry), and several checklists and questionnaires prepared for each work situation.

As a suggestion, examples of the OWAS, NIOSH, RULA and REBA methods. will be discussed.
The OWAS, applied in product design, results in postural information that must be changed or maintained, according to the situation, in the future product [8].

This tool is usually applied correctively in machines and / or workstations. It is suggested that this method be used to predict muscle problems, avoiding future corrective actions.

The RULA, REBA, OWAS and NIOSH tools, used in the investigative (informational) phase, helps the designer to verify postural problems of humanmachine interaction in order to determine customer's requirements. Their application on competing products can also be efficient, verifying strengths to be kept and weaknesses to be improved.

There are many needs when it comes to the design of an equipment or product. As an example, one can cite the quantification of manual lifting and carrying loads, which can cause musculoskeletal disorders in the users / workers.

In this type of analysis, it is recommended the use of the NIOSH method.

NIOSH takes into account four basic aspects: epidemiologic (the study of diseases), psychological (which considers human behavior in a given situation), biomechanical (which takes into account the structures and functions of human biological systems) and physiological (study of the functions of living organisms). Based on this knowledge, this tool application is designed to prevent postural and muscle problems and to determine appropriate limits for manual loading.

Validation of prototypes can be widely used to verify if the users' requirements were met, avoiding damage.

The RULA is a system developed by Corlett and Mcatamney in 1993 to assess the exposure of individuals to postures, forces and muscle activities that may contribute to the development of musculoskeletal problems. It is based on direct observation of the positions taken by the arms, forearms, hands, neck and trunk, the lifting of loads and use of the muscles involved. This method of postural analysis allows the designer to understand the actual conditions of use of a product. Depending on the analysis and its outcome it will be required implementations in the new product, i.e. the product development is focused on user's needs [7].

The REBA method (Rapid Entire Boby Assessment), used to perform postural analysis and risk assessment, starts with a systematic observation of work cycles, scoring the postures of the trunk, neck, legs, loads, arms, forearms and wrists in 
specific tables to each group. After the score of each group, the final score is obtained, which must be compared to a table of risk and action levels on a scale ranging from 0 to 4 [15].

These tools were cited as an example so that the professional gets to know some tools that can give him support and parameters in postural analysis, outside of subjective thinking.

With the use of these four methods, postures and loads management problems can be identified and addressed in the conceptual phase.

Another tool that can be used in the informational phase is the discomfort map, documents with the human body figure divided into sections. The user points to the place where he feels or senses a problem and then immediately score subjectively the degree of discomfort perceived in each segment.

These suggestions to the informational phase can be concluded predicting that every analysis and ergonomic tool that runs on a product can be applied to a competing product, helping to define project requirements. Afterwards it can be applied to mockups and prototypes.

At the end of this phase, the professional will have a description of users' groups, setting anthropometric, postural, physiological and psychosocial information.

\subsection{Conceptual phase}

In the conceptual phase, the designer, engineer or project planner, after setting the design requirements, works on the product form and dimensions. For this, ergonomics can contribute with some information, tables and tools.

To be able to dimension any product where interaction with people takes place, it is necessary to use anthropometric tables. Anthropometry treats physical body in terms of size and proportions, serving as a database for product and service ergonomic design.

Three-dimensional (3D) anthropometry can provide valuable information for ergonomic product design, offering greater safety and health. Three-dimensional data can be a great help to overcome the traditional design disadvantages, since they can provide information on the 3D surface geometry [13].

The disadvantage of traditional anthropometry is that it can only offer one or two dimension data to designers and ergonomists, this limitation keeps them from understanding and studying the human body anatomical features in three dimensional spaces. As mentioned, in order to provide better support to the designer in human body measurement and modeling, 3D anthropometry must be considered. CAD (computer aided design) is a common draw tool for design professionals. In $2 \mathrm{D}$ or $3 \mathrm{D}$ environment, it is necessary to use anthropometric mannequins, in order to help defining the product dimensions [19].

Through simulations in virtual environments, the interaction of man with the object can be simulated, anticipating problems that would be found only with a functional prototype.

Still in this form definition phase, the mock-up can be implemented, as the product gets the physical volume when out of the virtual, it also has low production costs and ensures a tactile interaction analysis. If the mock-ups are built, real time simulations can be performed and even some of the tools presented in the informational phase may be applied. Photographs and filming can assist in the mock-up analysis record. By the end of the phase, the project will have a correct sizing, following anthropometric tables and with the use of ergonomic tools, which simulate human-machine interaction in $2 \mathrm{D}$ and $3 \mathrm{D}$ environments.

\subsection{Preliminary phase}

The methodologies studied show no tool for this stage, however, when a physical prototype is built, much information can be extracted and used from the analysis.

Postural tools used in informational phase serve as developed product validation tools. In general, the methods and analyses that provide users' information to informational phase should be resumed in the prototype analysis.

Through a Focus Group, the user will be observed, questioned and he will give support to the solutions previously found through ergonomic analysis.

It is important to study the practical effects of such projects using both technological and ergonomic methods [10].

This test is of great importance when used as a project tool. A prototype will be developed from a subset of the alternatives concepts, comparative tests will be performed with users to implement and quantify the difference in resources used by the project over a period of analysis, compared with existing products. The ergonomics involved in the relative success or failure of projects should be evaluated together with technological considerations, to improve the method for the incorporation of the evidence on the technique application. When these tools are applied in the preliminary phase, the 
expected result will be the prototype validation in ergonomic requirements or itis reformulation up to the point that the product is optimum. See table 1 .

Table1

Proposed Positioning of the Tools

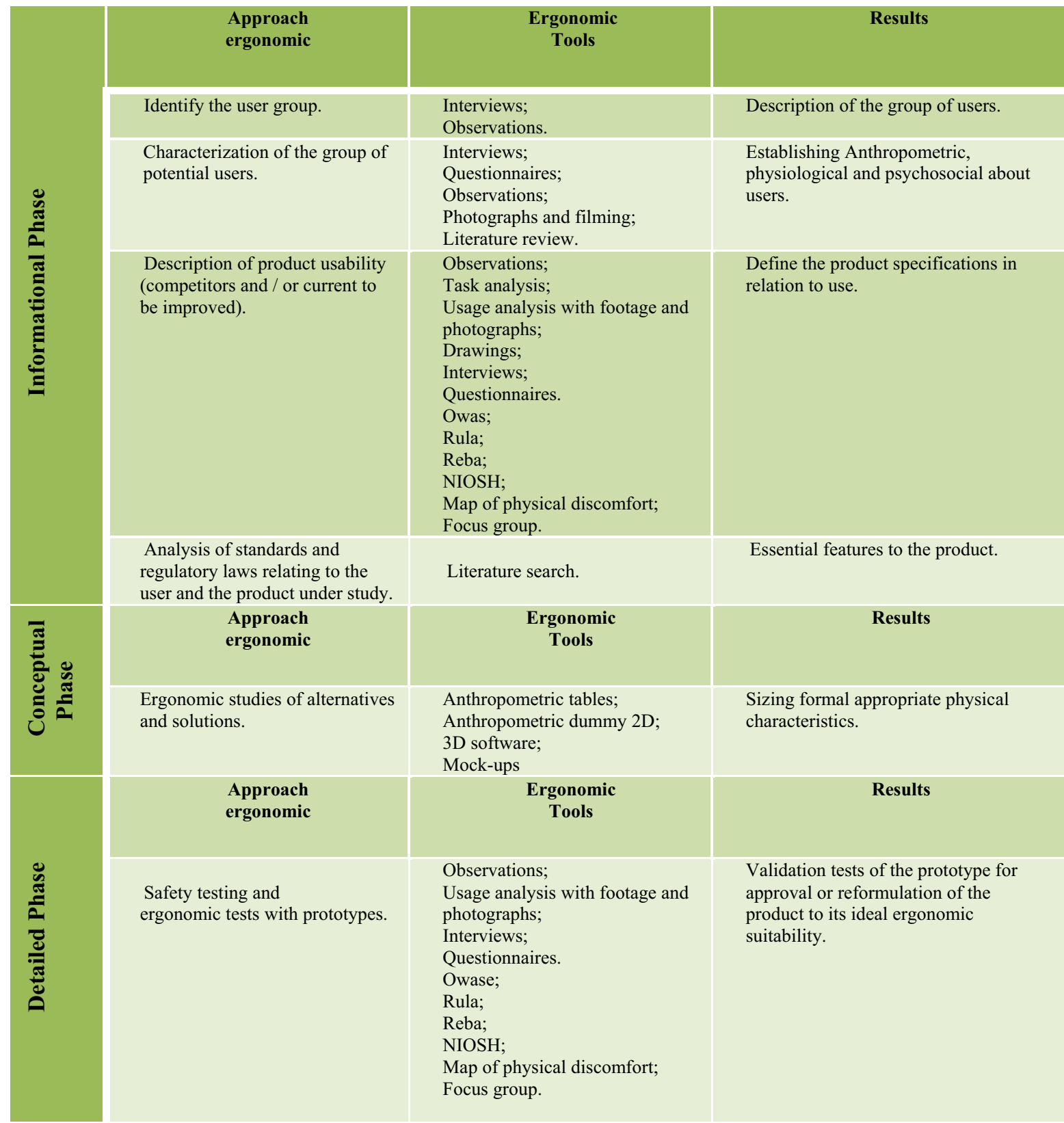




\section{Conclusion}

Literature review on the topic discussed revealed product design methodologies used by designers, engineers and ergonomists, identifying its scope, relevance and peculiarities.

Through the literature review, it was possible the understanding of design concept that describes the need to systematize the product development process, due to its scope and interdisciplinary.

Therefore, it was essential to verify the influence of the product process development cost and the influence of this cost in the decision making process. The importance of proper project planning was verified, as well as the importance of considering ergonomics from the beginning of the design methodology.

According to the studies, the product design methodologies directed to a more complete management of the whole project were identified, and two of the models were analyzed afterwards.

It was found that there are some ergonomic methodologies that indicate which tools should be used in each phase of product development.

In its initial part, this paper identified a deficiency in the ergonomic approaches for design methodologies. The methods used by ergonomists do not present in a clear and explicit way which ergonomic tools should be used in each product development phase. Through literature, it has been proven the importance of using ergonomic concepts from the early stages of the methodologies.

Ergonomics uses the knowledge of several other areas such as physiology, biomechanics, psychology, occupational safety, among others. It currently has investigative approaches that can easily be present in the product development process.

The proposal of submitting the tool that best fits in the product design process is intended to guide students and professionals responsible for new products, avoiding the user frustration due to complicated and awkward interactions with products. This will ensure better performance and financial health to the companies.

This paper suggests the introduction of ergonomic tools in all phases of product development, making it clear to the methodology user which is the most appropriate tool for each phase.

It is vital for the professional who works in product development to have knowledge beyond design methodologies. It is also necessary to understand how human behavior works, both cognitive and physical, when performing a task interacting with products. Thus, studying ergonomics, the professional can perform design activities efficiently, when the product is user-centered. Finally this study showed the importance of considering ergonomics as a whole, in all phases of product development.

\section{References}

[1] Baxter, Mike. Projeto de produto: guia prático para o design de novos produtos. 2. ed. rev. São Paulo: Edgard blucher, 2006.

[2] Burdek, Bernhard E. Design: História, teoria e prática do design de produtos São Paulo: Edgard Blücher, 2006.

[3] Cardoso, Rafael. Uma introdução à história do design. 3. ed. rev e ampl. São Paulo: Edgard Blücher, 2008.

[4] Daniellou, F. Questões epistemológicas levantadas pela ergonomia de projeto. In: DANIELLOU, F. A Ergonomia em busca de seus princípios. São Paulo: Edgard Blücher, 2004.

[5] Du, Jan; Weerdmeester, Bernard. Ergonomia prática. 2. ed. São Paulo: Edgard Blücher, 2004.

[6] Freixo, Osvaldo M., Toledo, José C. de. Gestão dos Custos do Ciclo de Vida do Produto durante seu Processo de Desenvolvimento. IV Congr. Bras. Gestão e Desenv. de Produtos - Gramado, RS, Brasil, 6 a 8 de out de 2003.

[7] Guimarães, L. B. de M. Ergonomia de Produto (2) (5 ed.). 5. ed. Porto Alegre: FEENG, 2006.

[8] Iida, Itiro. Ergonomia: projeto e produção. São Paulo: Edgard Blücher, 2005.

[9] Lobach, Bernd; Van Camp, Freddy. Design industrial: bases para a configuração dos produtos industriais. São Paulo: Edgard Blücher, 2001.

[10] Lockton, Dan, David Harrison, e Neville A. Staton. "The Design with Intent Method: A design tool for influencing user behaviour." Applied Ergonomics, n. 41 (2010): p. 382-392.

[11] Moraes, Anamaria de; Mont'alvão, Cláudia. Ergonomia: conceitos e aplicações. 2.ed Rio de Janeiro: 2 AB, 2000.

[12] Morgan, James M. Sistema Toyota de desenvolvimento de produto:integrando pessoas, processo e tecnologia - Porto Alegre: Bookman, 2008. 392p.

[13] Niu, Jianwei, Zhizhong LI, e Gavriel Salvendy. "Multiresolution description of three-dimensional anthropometric data for design simplification." Applied Ergonomics, n. 40 (2009): p. 807-810.

[14] Pahl, G. et al. Projeto na engenharia: fundamentos do desenvolvimento eficaz de produtos, métodos e aplicações. 1. ed. São Paulo: Edgard Blücher, 2005.

[15] Pavani, Ronildo Aparecido, e Osvaldo Luiz Gonçalves Quelhas. "A avaliação dos riscos ergonômicos como ferramenta gerencial em saúde ocupacional." XIII SIMPEP. Bauru, SP, Brasil, 2006.

[16] Rozenfeld, Henrique et al. Gestão de desenvolvimento de produtos: uma referência para a melhoria do processo. São Paulo: Saraiva, 2006.

[17] Sagot, Jean-Claude et al . Ergonomics in product design: safety factor. Safety Science 41, 2003.

[18] Vidal, Mario Cesar. Ergonomia na empresa. Útil, prática e aplicada 2.ed. Rio de Janeiro: Virtual Científica, 2002.

[19] Zhang, B., I. Horváth, J.F.M. Molenbroek, E C. Snijders. "Using artificial neural networks for human body posture prediction. " International Journal of Industrial Ergonomics, $\mathrm{n}$. 40 (2010): p.414-424 